\title{
Micromechanical Devices for Intravascular Drug Delivery
}

\author{
Michael L. Reed, ${ }^{*} \dagger$ Clarence Wu, ${ }^{\ddagger}$ James Kneller, ${ }^{\ddagger}$ Simon Watkins, ${ }^{\ddagger}$ David A. Vorp,${ }^{\ddagger}$ Ahmed Nadeem, ${ }^{\ddagger}$ \\ Lee E. Weiss, ${ }^{\S}$ Keith Rebello," Mark Mescher,, A. J. Conrad Smith, ${ }^{\ddagger}$ Warren Rosenblum, ${ }^{\ddagger}$ and \\ MARC D. FELDMAN ${ }^{\ddagger}$
}

Contribution from Department of Electrical Engineering, University of Virginia, Charlottesville, Virginia 22903, Department of Medicine, University of Pittsburgh School of Medicine, Pittsburgh, Pennsylvania 15213, Robotics Institute, Carnegie-Mellon University, Pittsburgh, Pennsylvania 15213, and ECE Department, Carnegie-Mellon University, Pittsburgh, Pennsylvania 15213.

Received March 27, 1998. Accepted for publication May 7, 1998.

\begin{abstract}
Microfabrication technology, more commonly applied to the manufacture of integrated circuits, can be used to build devices useful for mechanical delivery of drugs and genes. Microprobes fabricated using silicon micromachining have been used to deliver DNA into cells as an alternative to bombardment and microinjection. This idea can be extended to intravascular stents with integrated microprobes capable of piercing compressed plaque and delivering anti-restenosis therapies into coronary arteries. Preliminary experiments using filleted rabbit arteries have demonstrated transection of the internal elastic lamina. New nonplanar microfabrication technologies are necessary for creating practical devices with cylindrical symmetry; a promising possibility is to use microfabricated structures of anodic metal oxides.
\end{abstract}

\section{Introduction}

Microfabrication technologies, used primarily in the manufacture of electronic integrated circuits, have been applied to several biomedical related areas. Most of these applications are in diagnostics (i.e., microfabricated pressure transducers, thermometers, ultrasonic sensors, and the like). More recently, there has been considerable interest in so-called "lab-on-a-chip" applications where a large number of chemical or biological assays are performed in parallel. M ost of these applications are straightforward extensions of microelectronic processing and silicon micromachining, in which precise patterns are etched or otherwise configured onto a planar substrate of semiconductor silicon. The dominant tool used in all planar processing is photolithography, in which information in the form of a two-dimensional map is transferred from a glass plate (the mask) to a light-sensitive organic film (the photoresist). Because this process affords parallel manufacturing, with many thousands of devices fabricated simultaneously, enormous economies of scale result, which drive the cost per individual device down as this technology is introduced.

In this paper, we discuss the use of microfabrication technology applied to mechanical drug injection devices. ${ }^{1}$ Our goal is to develop an indwelling coronary stent with micromechanical probes capable of piercing compressed plaque and delivering anti-restenosis therapies into the arterial wall. In the next sections, we first introduce the idea of using mechanical microprobes to transfer DNA into cells. We then describe the gene stent and experiments

* Corresponding author. Phone: 804-924-6309. Fax: 804-924-8818. E-mail: reed@irginia.edu.

+ Department of Electrical Engineering.

₹ Department of Medicine.

§ Robotics Institute.

" ECE Department.

(C) 1998, American Chemical Society and American Pharmaceutical Association with tissue penetration using microprobes fabricated from silicon. We then discuss the limitations of conventional planar microfabrication technology for this application, and conclude with an alternative method that facilitates the fabrication of three-dimensional microstructures.

\section{DNA Transfer Using Microprobes}

Several gene transfer techniques have been developed for the introduction of foreign genes into both plant and animal cells. One of the more commonly used methods is cell bombardment, in which small particles coated with genetic material are ballistically transported into target cells. ${ }^{2}$ Alternatively, el ectrophoration techniques can be used; this involves the use of an electric field to transport the material across the cell wall. ${ }^{3}$ An effective but laborious and time-consuming method needing highly skilled practitioners is direct microinjection. In this technique, a fine hypodermic needle is inserted into the target cell by direct manipulation under a microscope; the DNA is then directed through the needle lumen.

Another method is to use micromechanical piercing structures, as shown in Figure 1. These structures, fabricated in dense arrays using silicon micromachining techniques, are $\sim 80 \mu \mathrm{m}$ high and have an extremely sharp point, with a radius of curvature of $<0.1 \mu \mathrm{m}$. When the microprobes are coated with genes and pressed into cells or tissues, the sharp tips penetrate into the cells and effect the transport of genetic material, which is subsequently expressed in the target cells and their progeny. Successful expression of foreign genes using this technique has been demonstrated in the nematode Caenorhabditis e egans ${ }^{4}$ and tobacco leaf cells. ${ }^{5}$ More recently, we have shown that transfection can occur in mammalian cells. In these experiments, smooth muscle cells from rat arteries were cultured. A solution containing DNA was centrifuged onto microprobe arrays and pressed into smooth muscle cell monolayer samples. Figure 2 illustrates typical results. At the top is shown a control sample in which no DNA was applied to microprobe tips. The regular pattern of dots, spaced $250 \mu \mathrm{m}$ apart, are depressions caused by the microprobes as they were pressed through the cultured cells. The bottom picture illustrates successful incorporation of $\beta$-galactosidase into the smooth muscle cells, as evidenced by the blue stains. N ote that the staining is not coincident with the location of probetips, which means that either the DNA was transported laterally away from the tips, or more likely the cells have rearranged themselves after transfection. ${ }^{6}$ This result, coupled with the lack of any evidence of dead cells, indicates that microprobes do not cause catastrophic cell injury during the transfection process.

Microprobe arrays are attractive as a research tool for genetic engineering because they are relatively inexpen- 


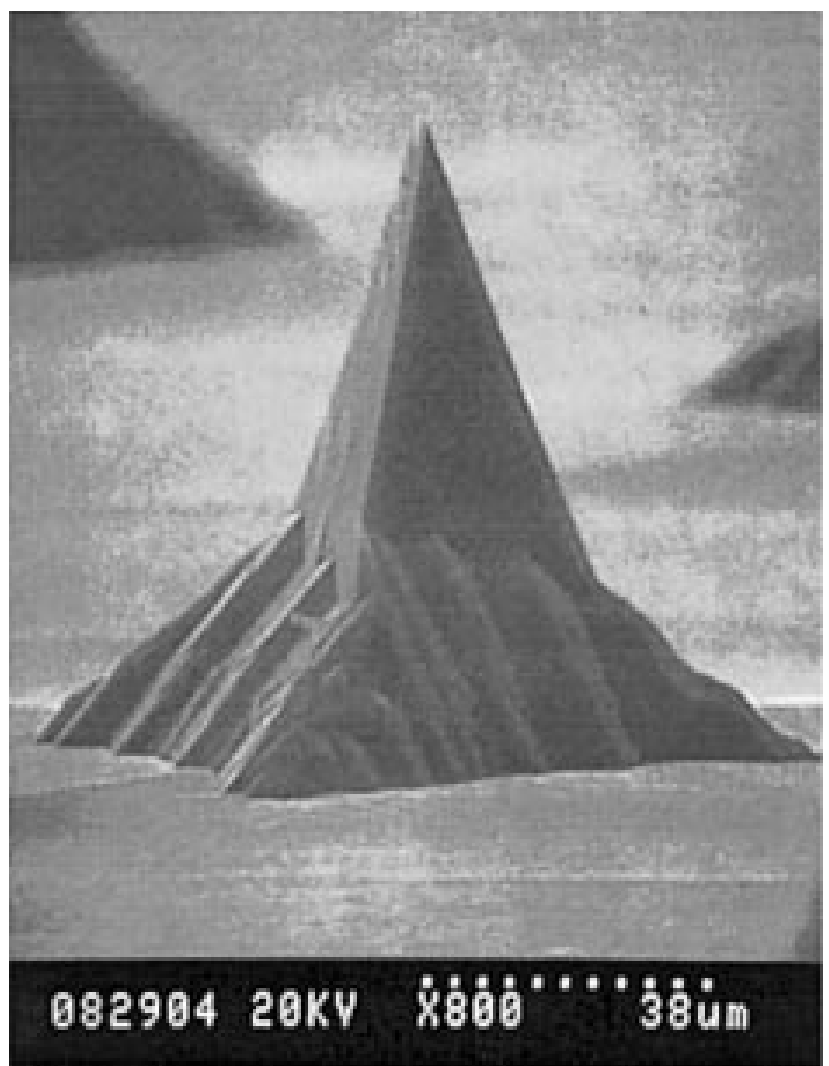

Figure 1-Silicon microprobe fabricated by anisotropic silicon etching. Arrays of microprobes are micromachined onto planar silicon wafers using photolithography and wet chemical etching. The sides of the microstructure are defined by crystalline planes inside the silicon substrate.

sive, effective, and easy to use, especially in comparison with microinjection. A natural question is, therefore, can such devices be used in vivo for therapeutic applications?

\section{Restenosis}

Heart disease, evidenced by the progressive narrowing of coronary arteries by atherosclerotic plaque, continues to be a leading cause of death in the United States and worldwide. Commonly used transcatheter therapies for restoring lumen patency include balloon angioplasty, atherectomy, and coronary stenting. Despite the overall initial success of these procedures, approximately one-fifth to onethird of all patients will suffer restenosis (re blockage) within 6 months of the initial procedure. Numerous pharmacological agents and genes have been shown to inhibit restenosis in animal models; however, all have failed in human trials. A chief difficulty is that local delivery methods relying on diffusion or pressure gradients are unable to transport therapeutic agents through the compressed layer of plaque, which can be up to $200 \mu \mathrm{m}$ thick.

Balloon angioplasty is essentially a trauma-inducing event. The body responds to this trauma with a set of responses, including elastic recoil, smooth muscle cell migration and proliferation, associated extracellular matrix synthesis, vessel wall remodeling, and thrombus organization and incorporation. ${ }^{7-10}$ The end result is the formation of a mass of material integrally coupled with the intimal wall. Elastic recoil of the vessel wall takes place after balloon deflation. Minutes following the injury, a thin layer of platelets and fibrin is deposited on the injured lumen. Within hours to days, inflammatory cells begin to infiltrate the site and vascular smooth muscle cells begin to migrate

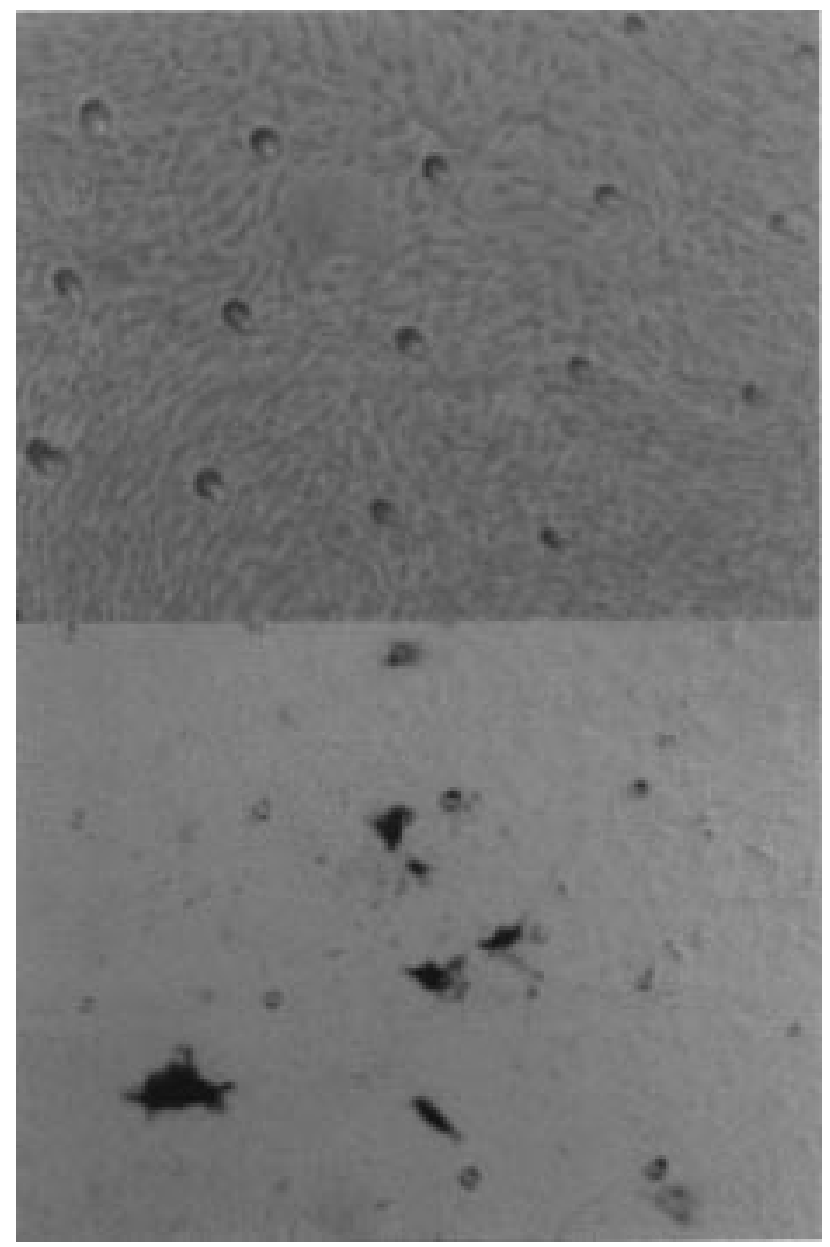

Figure 2-Images of transfected rat smooth muscle arterial cells. (Top) Control sample, with no DNA applied to microprobe tips. The regular array of dots are the depressions of the microprobes into the plastic Petri dish. The microprobes are spaced $250 \mu \mathrm{m}$ apart. (Bottom) Blue staining illustrates successful incorporation of $\beta$-galactosidase into the smooth muscle cells. Note that the staining is not coincident with the location of probe tips.

toward thelumen. These smooth muscle cells then convert from their normal contractile phenotype to a synthetic phenotype in which they hypertrophy and begin to secrete extensive extracellular matrix, thereby increasing the thickness of the intima. ${ }^{11-14}$ These events are collectively termed "neointima" formation. During this time, the lumen surface is colonized by endothelial cells that slowly regain their normal barrier function and secretory functions in making tissue plasminogen activator and endothelial derived relaxation factor. The media remodels to adjust for the restored lumen size.

If the vessel response to injury is excessive, most or all of the gain in lumen diameter produced by the initial interventional procedure may be lost to the healing process, with return of a severe stenosis and ischemic symptoms. During the 6-month period when clinical restenosis occurs, different arteries appear to undergo varying degrees of proliferation and vessel remodeling, resulting in an observed patient-to-patient variation in the amount of late loss in lumen diameter. There tends to be a linear relationship between the late loss in lumen diameter caused by the healing response and the acute gain in lumen diameter caused by the intervention. ${ }^{15}$ One consequence of this finding is that larger lumen diameters immediately after intervention translate into larger lumen diameters at the end of this 6-month healing time. The acute gain in the lumen produced by the intervention is only partially 


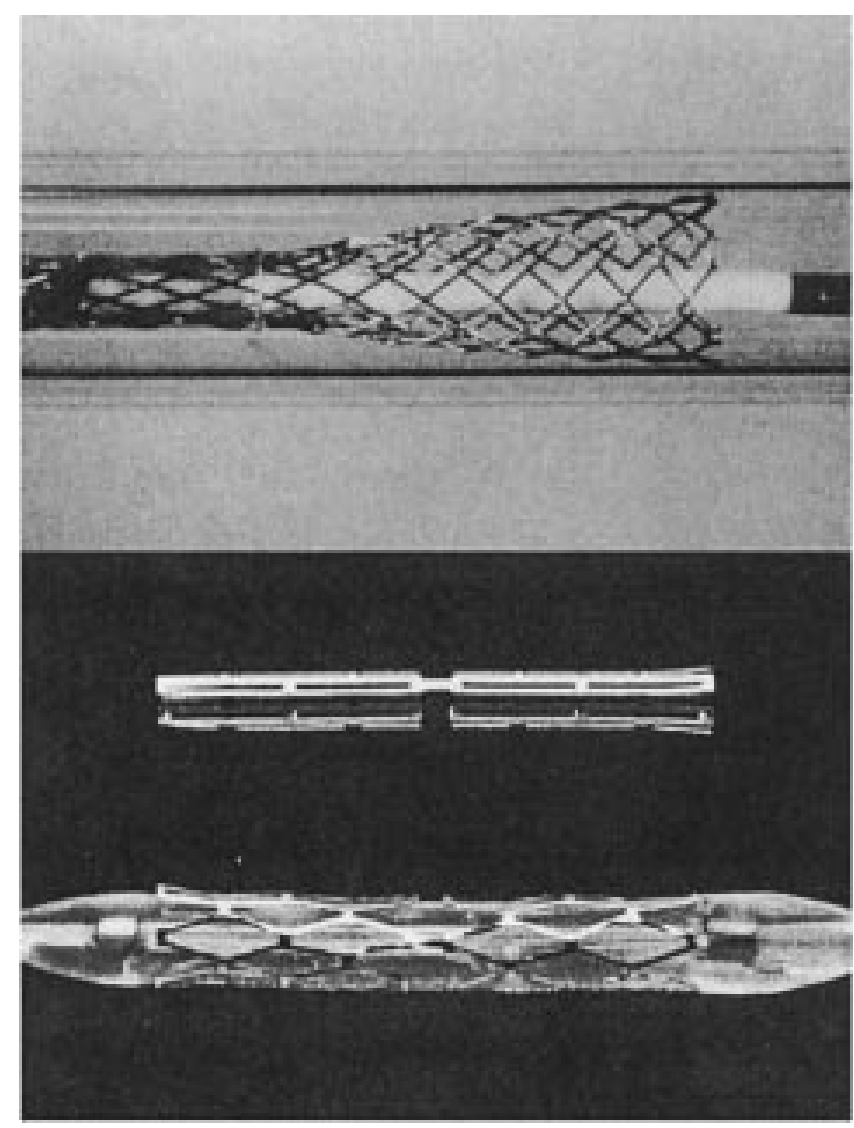

Figure 3-(Upper) Wall stent. (Lower) Palmaz-Schatz stent. (Data from Baim and Grossman. ${ }^{17}$ )

lost during the repair process, resulting in a long-term net gain in lumen diameter.

Various mechanical devices have been developed in search for a way to reduce the incidence of restenosis. Of these mechanical devices, only intracoronary stenting has been shown to reduce the incidence of restenosis $(32 \%$ versus $42 \%, p<0.05) .16$ The success of stenting has been attributed to the elimination of elastic recoil and fibrotic vessel contraction. However, stents aggravate intimal hyperplasia, the major histologic component of restenosis. Two kinds of stents, the Wall stent and the Palmaz-Schatz stent, are shown in Figure 3.

Further reduction of restenosis could be accomplished by delivering drug or gene therapy to the site of injury. Several attempts have been made to deliver pharmacol ogic agents with various catheter-based systems locally in high concentrations to overcome the tolerated dose limitations of systemically administered therapeutics. These systems have been recently reviewed by $\mathrm{H}$ ofling and Huehns, ${ }^{18}$ and can be categorized as diffusion through close contact (i.e., hydrogel balloons, coated stents), pressure-driven diffusion (such as porous balloons and infusion sleeves), and mechanically assisted transport (needle catheters, iontophoretic balloons, cutting balloons). With these devices, successful delivery of pharmacological agents as well as genetic materials have been demonstrated in normal arteries.19-21 However, both the internal elastic lamina (IEL) and the compressed atherosclerotic plaque present in diseased vessels act as a barrier, and none of the available local delivery devices are capable of penetrating these layers. ${ }^{22}$ For example, research by Feldman ${ }^{23}$ showed that delivery of reporter genes to atherosclerotic arteries was one-tenth as efficient as in normal arteries.

Our goal is to engineer a stent capable of overcoming these barriers and delivering a therapeutic agent to prevent smooth muscle cell proliferation and thus reduce the incidence of restenosis. A diagram of the device is shown in Figure 4. A metal stent is studded with microprobes that could be capable of piercing atherosclerotic plaqueand transecting the IEL. Therapeutic agents coating the stent can then be delivered into the vessel wall as the stent is deployed by an inflation balloon.

Because micromachined probes have been shown to transfect mammalian smooth muscle cells, there are, broadly speaking, two issues to be considered for this device. The first issue is whether a microprobe is capable of piercing through atherosclerotic plaque, and if, so, what is the appropriate height, geometry, and pressure needed. Second, how can a three-dimensional structure like that shown in Figure 4 be fabricated? In the remainder of this paper we address these two points.

\section{Microprobe Penetration into Blood Vessels}

The scanning electron micrograph in Figure 5 illustrates in cross-section a silicon microprobe, $\sim 80 \mu \mathrm{m}$ high, inserted into a rabbit iliac artery. Although the microprobe is quite sharp, it is insufficiently tall to break through the internal elastic lamina. Instead, the IEL is deformed around the microstructure.

We conducted a number of experiments to investigate the interaction of microprobes and blood vessels as a function of microprobe height and applied pressure. Three different microprobe geometries were evaluated in both normal and atherosclerotic vessels. For each of these groups, the microprobe-arterial wall interactions were examined at pressures of 100,300, and $500 \mathrm{mmHg}$ to simulate the intraluminal pressures seen clinically during stent deployment. Details of these experiments are re ported elsewhere;22,24 here we give an abbreviated description of the procedure and summarize the main results regarding applied pressure.

Six-month- to two-year-old, 3-4 kilogram, New Zealand white rabbits were used in this study. Atherosclerotic lesions were created by feeding the rabbits a hypercholesterolemic diet containing 5\% cholesterol and 7\% peanut oil for a period of 3 weeks. At the conclusion of this period, arterial balloon injury was performed using a Fogarty $2 \mathrm{~F}$ catheter. ${ }^{25}$ The rabbits were returned to the animal facility and the hyperchol esterol emic diet was resumed for another 3-5 weeks to complete atherosclerotic lesion formation. Atherosclerotic and normal iliac arteries were harvested from the rabbits and filleted using the tissue handling protocol developed by Fry et al. ${ }^{26-28}$

The tissues were mounted, endothelial side up, in a device designed to simulate the circumferential vessel distention (typically 10 to $30 \%$ ) caused by stenting. Microprobe arrays were placed on the lumen (now a planar surface due to the filleting procedure) and a calibrated pressure was applied. Following microprobe application, the culture medi um was replaced with $2.5 \%$ gluteral dehyde in phosphate buffer for 20 min. ${ }^{22}$ This time period was sufficient for the fixative to preserve the deflections and/ or incisions caused by the microprobes. Following tissue fixation, the pressure and microprobes were removed, and excess fixative was pipetted from the tissue chamber. All tissue samples were fixed in gluteraldehyde within $3 \mathrm{~h}$ of death. The fixed tissues were sectioned and imaged (SEM, TEM, and light microscopy) to observe the effects of the microprobes.

Tissue samples processed for light microscopy were cryosectioned by rapidly freezing them in isopentane chilled in liquid nitrogen and microtoming them to produce samples $\sim 5-7 \mu \mathrm{m}$ thick. Approximately 200-250 sections were collected per tissue sample. All collected samples 


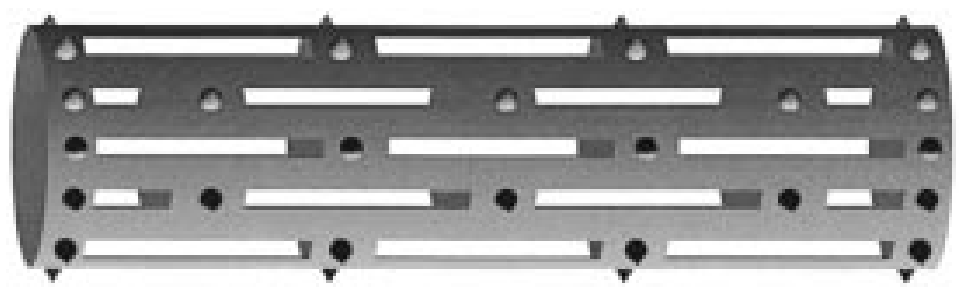

Figure 4-Micromechanical gene stent. A metal stent is studded with microprobes that can penetrate atherosclerotic plaque and deliver genes or drugs to the vessel wall.

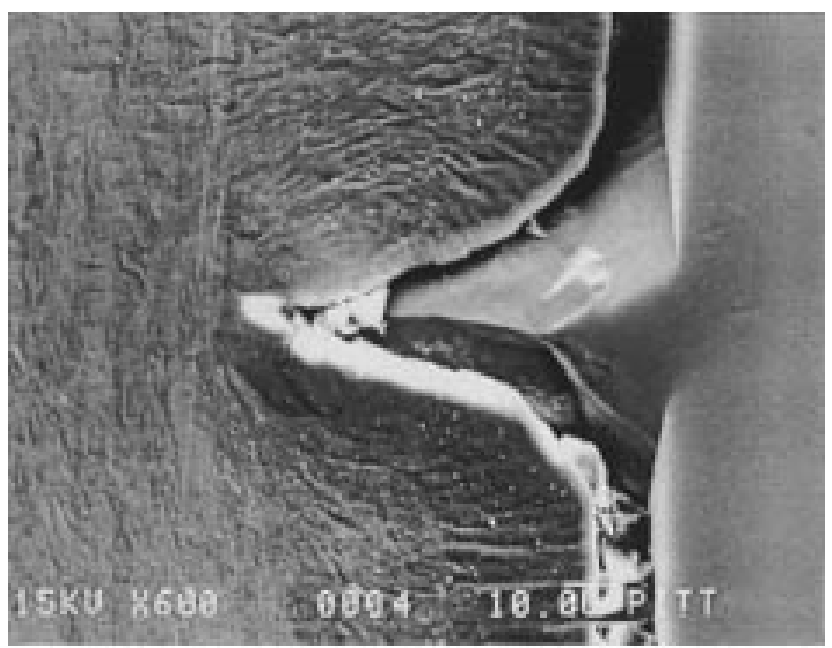

Figure 5-Incomplete microprobe penetration. A silicon microprobe, $\sim 80 \mu \mathrm{m}$ high, deforms the internal elastic lamina of a rabbit iliac artery, but does not penetrate through it.

were screened with a 10X light microscope for microprobe penetrations. Slides that contained penetrations were stained and processed for data collection. Normal iliac artery sections were stained with hematoxylin and eosin (H\&E). ${ }^{29}$ The hematoxylin stained the cell nuclei blue, and the eosin stained the cell cytoplasm red. Atherosclerotic iliac artery cryosections were stained with Oil red O-2propanol method, which uses hematoxylin as a counterstain. ${ }^{30}$ The Oil red O-stained the lipids red, and the hematoxylin stained the cell nuclei blue.

Figures 6, 7, and 8 show cross-sectional optical micrographs of tissues where arrays of $140-\mu \mathrm{m}$-high microprobes were applied with two different pressures. In each of these micrographs, the vessel adventitia is on top, whereas the vessel media, bounded by the external elastic lamina (center) and internal elastic lamina (bottom), is beneath. Figure 6 illustrates a normal vessel where the microprobes were applied with a pressure of $100 \mathrm{mmHg}$. There is some media compression, but deep penetration into the media does not occur. IEL transection was confirmed by fluorescence microscopy (not shown). Compression of the media was also noted with $65-\mu \mathrm{m}$-high microprobes at all applied pressures, however, IEL transection did not occur with these shorter microprobes.

Figure 7 shows a normal tissue subjected to an array of $140-\mu \mathrm{m}$-high microprobes at a higher pressure of 500 $\mathrm{mmHg}$. Here, it is clear that the microprobes have successfully transected the internal elastic lamina, the media, and the external elastic lamina. All other normal vessel cross-sections obtained using these same conditions show transection of the IEL, although not all show penetration through to the adventitia.

Figure 8 shows a cross-section of atherosclerotic vessels penetrated by $140-\mu \mathrm{m}$-high microprobes at $500 \mathrm{mmHg}$. The plaque is visible in the top micrograph as large red areas. The bottom image is a fluorescence micrograph that dearly
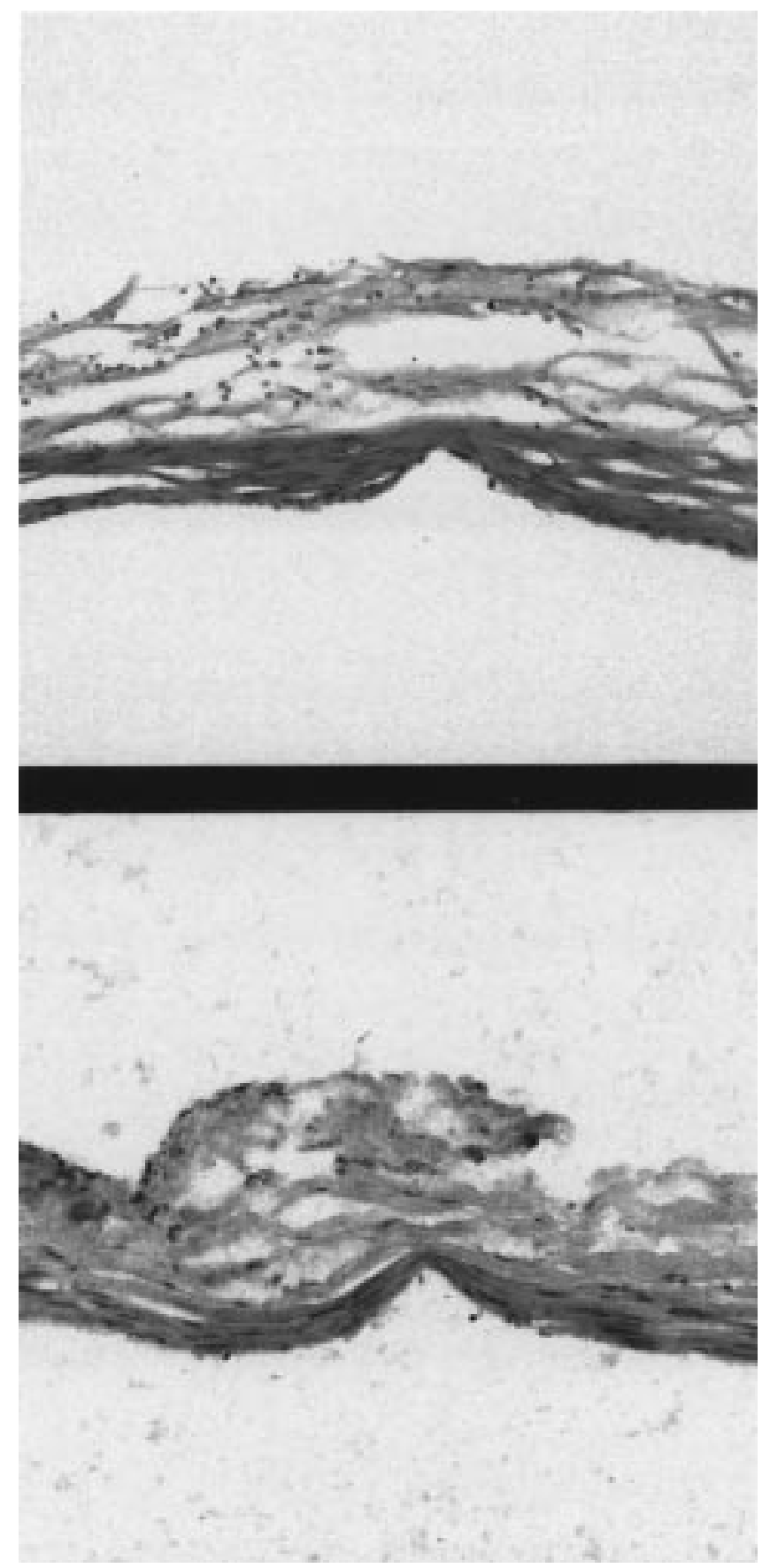

Figure 6-Cross-sectional optical micrographs of incomplete microprobe penetration in a normal vessel. In these photos, 140- $\mu \mathrm{m}$-high microprobes were applied with a pressure of $100 \mathrm{mmHg}$. (In these and the following crosssections, the top, lightly stained areas are the vessel adventitia; the lower regions correspond to the vessel media.)

shows the transection of the internal elastic lamina (dull blue). The area between the two small arrows indicates where the IEL is no longer continuous, having been 

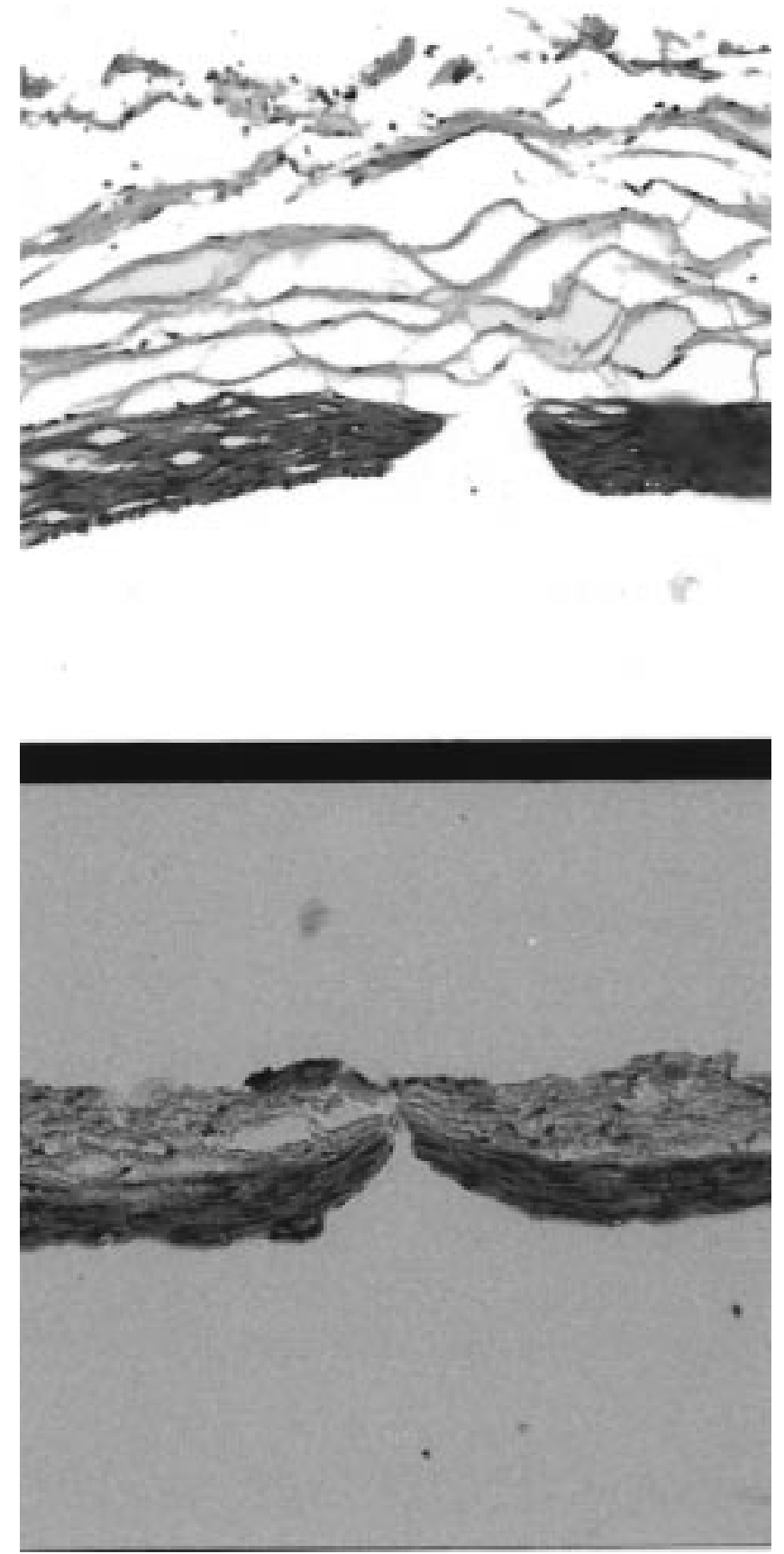

Figure 7-Cross-sectional optical micrographs of microprobe transection through the internal elastic lamina, media, and external elastic lamina in a normal vessel. Here, $140-\mu \mathrm{m}$-high microprobes were applied with a pressure of $500 \mathrm{mmHg}$.

disrupted by the microprobe. Other cross-sections indicate that the success of transection depends strongly on the thickness of the plaque, and the degree to which it covers the vessel intima.

These results show that microprobes of sufficient height that are applied under the appropriate conditions are capable of transecting the arterial wall in both normal and atherosclerotic vessels. However, for clinical application, the microprobes must be taller than those used in these experiments to penetrate through the plaque to reach the media. A therapeutic agent coating the microprobes can thus be delivered through the plaque into the vessel media; alternatively, microprobes fabricated with internal lumens would act as a conduit for drugs or genes delivered through a balloon.

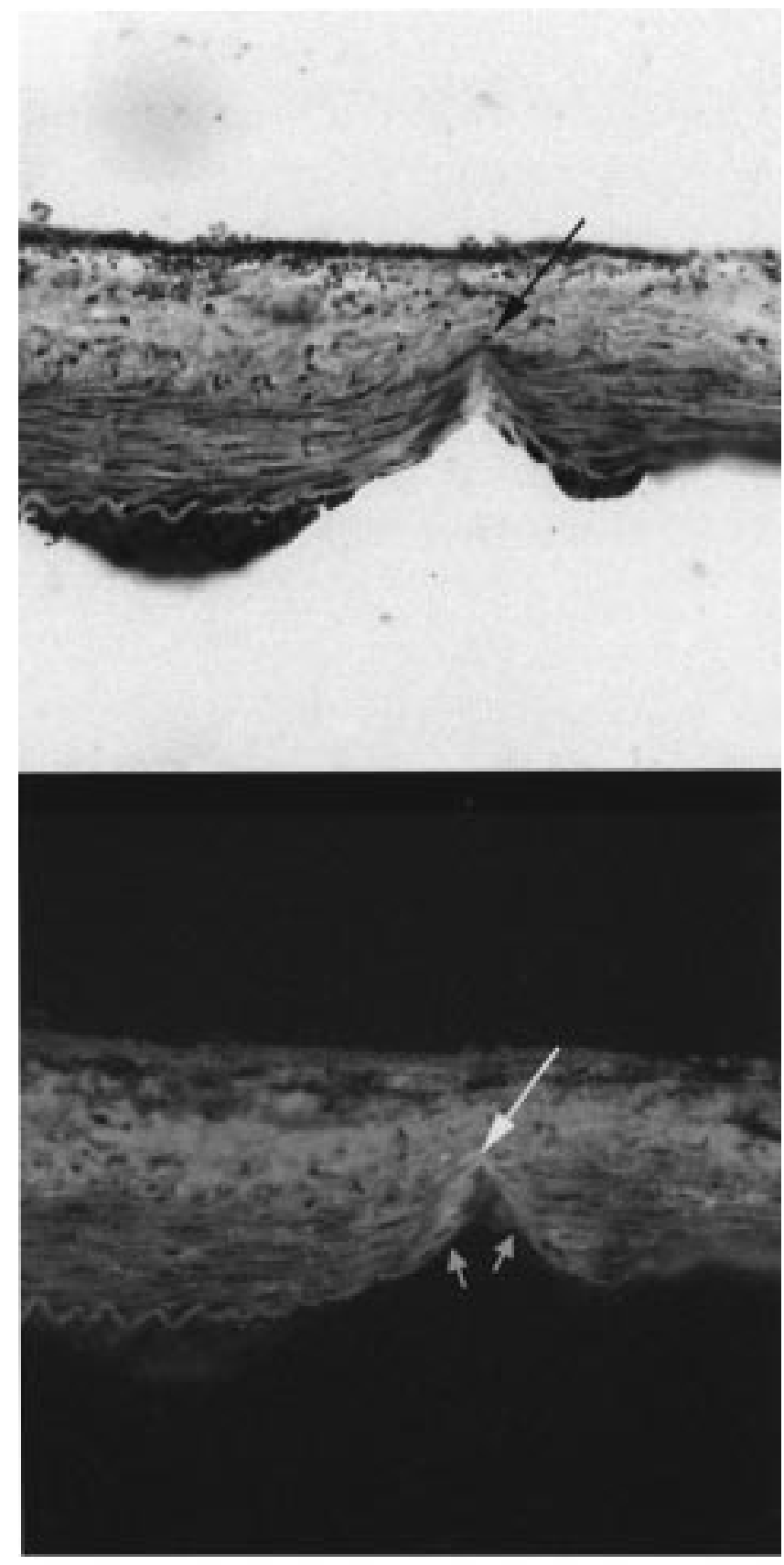

Figure 8-Cross-sectional optical micrographs of microprobe transection through the internal elastic lamina and media in a diseased vessel by 140 $\mu \mathrm{m}$-high microprobes applied with a pressure of $500 \mathrm{mmHg}$. (Top) Arrow indicates the location of microprobe application. The plaque is visible as large red areas. (Bottom) Fluorescence image shows the internal elastic lamina transected by the microprobe (two small arrows) and penetration through the media almost to the external elastic lamina.

\section{Microfabrication Issues}

The silicon microprobes used in these experiments (similar to Figure 1) were fabricated by anisotropic etching of crystalline silicon substrates. ${ }^{5}$ Briefly, silicon wafers are thermally oxidized to grow a thin $(\sim 1.5 \mu \mathrm{m})$ layer of $\mathrm{SiO}_{2}$ on the surface. The $\mathrm{SiO}_{2}$ layer is patterned using photolithography into an array of squares. The wafers are subsequently immersed in an aqueous solution of potassium hydroxide that etches the silicon at an appreciable rate $(\sim 1.5 \mu \mathrm{m} / \mathrm{min})$ but attacks the $\mathrm{SiO}_{2}$ at a much reduced rate. Consequently, the squares of $\mathrm{SiO}_{2}$ function as a mask 
that defines the microprobe locations. Moreover, the $\mathrm{KOH}$ silicon etching process has the interesting property that different crystalline planes in the silicon are etched at different rates. The four faces defining the microprobe pyramids are the fastest etching planes under the experimental conditions used. Hence, the angle of the microprobes is set by the properties of silicon crystals and the nature of the etching process, and it cannot be changed to an arbitrary value by varying the etching conditions.

The height of the microprobes is determined by the time at which the four fast etching planes that undercut the square $\mathrm{SiO}_{2}$ mask pattern meet at a point. Overetching beyond this point results in a shorter microprobe. Because the pyramids are defined by fast-etching planes, it is very easy to overshoot the process endpoint and end up with microprobes much shorter than the design value. Also, there is some natural nonuniformity in the etching process across the wafer diameter, so over etching is necessary to ensure proper microprobe geometry over the surface. These factors conspire to make the manufacture of silicon microprobe arrays with a consistent, uniform height quite problematic. Additionally, the microprobe height is a strong function of the pattern size, so it is impossible to make tall microprobes beyond a certain limiting areal density using this technique.

There exist other methods for etching microprobes from crystalline silicon using anisotropic etching. ${ }^{1,31,32}$ These processes use ion milling or plasma etching (i.e., reactants generated in a gaseous glow discharge) and are more flexible than $\mathrm{KOH}$ etching. However, they also suffer from uniformity problems, and it is likewise difficult to produce microstructures of the requisite height in large quantities using these techniques.

More importantly, both types of processes have been developed for etching silicon substrates, and are not well suited to other materials. For use as a research tool, microprobes fabricated from silicon are quite useful, but for clinical application, silicon devices have several drawbacks. Silicon is brittle and nonductile; it cannot be rolled, drawn, or forged. Conventional microfabrication technology is based on having extremely flat substrates; lithographic pattern transfer tools have a depth of focus of $<1$ $\mu \mathrm{m}$. Indeed, a major objective in manufacturing integrated circuits is to make the structures as planar as possible, to minimize dimensional variations arising from this depth of focus limitation. Thus, microfabrication tools and processes have largely been optimized to make shallow structures, which make the construction of "high-aspectratio" structures extremely difficult. (The aspect ratio of interest is the ratio of height out of the substrate plane, to the width in the plane. Conventionally, the width can range from $<1 \mu \mathrm{m}$ to several centimeters, but the height is practically limited to only a few micrometers.)

For the gene stent, these limitations preclude the use of silicon wafers processed with planar techniques. The chief difficulties are (1) a stent must have cylindrical symmetry to be deployed in a blood vessel and (2) the stent must expand and undergo plastic deformation upon balloon inflation. There are no existing parallel microfabrication processes capable of sculpting a three-dimensional object with features ranging over a multitude of length scales, and certainly none that would make silicon suitable for this application. Yet, the economies engendered by a lithographic manufacturing method argue strongly in favor of a parallel fabrication technique adapted to other materials and nonplanar geometries.

A candidate technology for this application is anodic oxide microfabrication. 33,34 In this technique, a metal substrate is anodized to the desired thickness. Anodic films can be made much thicker than the standard thin films

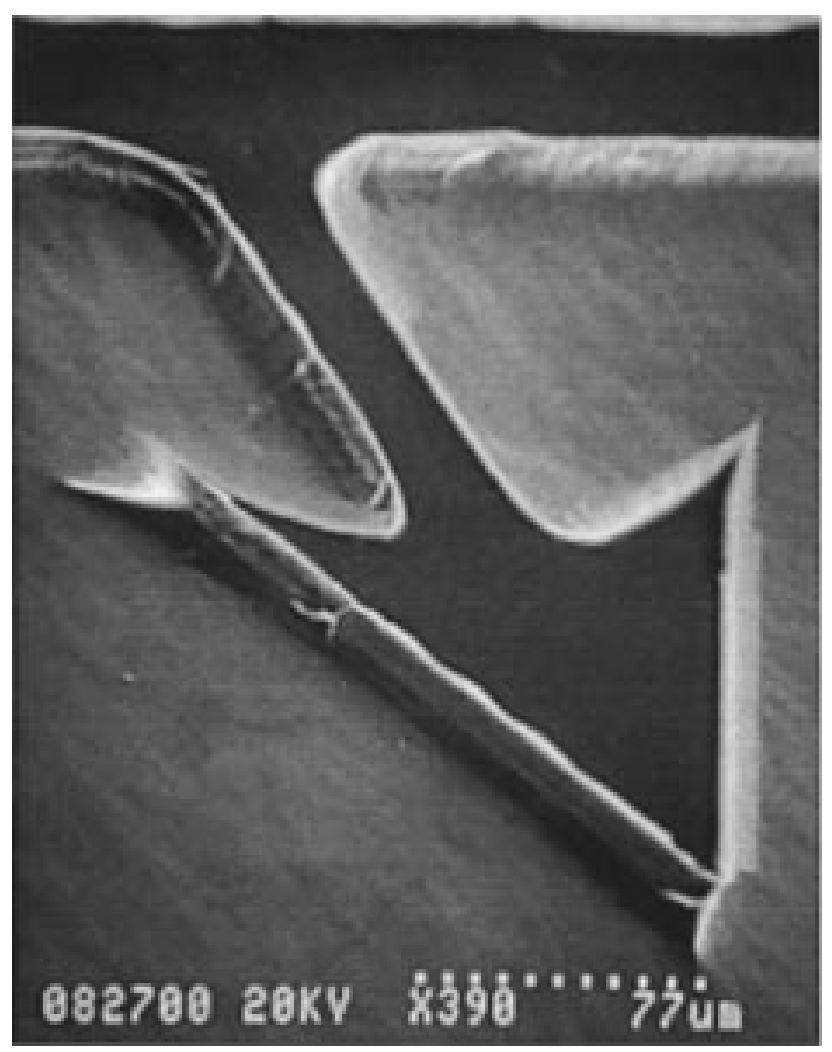

Figure 9-Test structure produced by the anodic oxide microfabrication process. The dark area is a $\mathrm{SiO}_{2}$ masking layer defined on an aluminum substrate. Elsewhere, the aluminum was anodized and the resulting anodic oxide stripped. The result is an aluminum microstructure with vertically oriented sidewalls that can be used as a template for a subsequent molding process.

produced by evaporation, sputtering, or chemical vapor deposition typically used in microsystems; thicknesses up to several hundred microns are easily attainable. The anodic oxide is patterned using standard photol ithographic methods and then etched. After etching, the edges of the masked microstructures are oriented normal to the substrate surface. The reason for this orientation arises from the internal structure of the anodic oxide, which consists of a honeycomb of pores oriented normal to the substrate. Etchant travels vertically down the pores, and then dissolves the anodic oxide laterally along the length of the pore. The result is high-aspect-ratio microstructures, tens to hundreds of microns high, which can be fabricated on metal substrates.

Alternatively, the masking step can be performed prior to anodization. In this process, a thin film of $\mathrm{SiO}_{2}$ is deposited on the substrate and patterned. When the sample is subjected to the anodization process, anodic oxide grows only in the unpatterned areas, where the $\mathrm{SiO}_{2}$ was removed. Elsewhere, the $\mathrm{SiO}_{2}$ prevents the formation of an anodic oxide. Stripping away the anodic oxide leaves behind high-aspect-ratio microstructures composed of metal, as shown in Figure 9. Using either process, the resulting artifact can be used as a mold to mass replicate the desired structures.

A key feature of anodic oxide microfabrication is the microstructures are aligned normal to the surface of the metal. This alignment is in contrast to silicon-based techniques, where the microstructures are aligned along the direction of illumination in the photolithographic pattern transfer step. Thus, if the metal substrate is machined or otherwise sculpted into a nonplanar shape, the microstructures will al ways be normal to the surface. For example, a mold for a cylindrical stent can befabricated by machining a semicircular groove in the metal and 
subsequently using the anodic oxide microfabrication process to pattern the groove wall with high-aspect-ratio microstructures. Two such molds, aligned face-to-face, would be a suitable template for electrodeposition or injection molding of the gene stent structure.

It should also be noted that these techniques would be useful in manufacturing other therapeutic microdevices. Although silicon micromachining has been employed for many biomedical devices, nearly all are directed toward diagnostic applications (for examples, pressure and temperature sensors, data tel emetry systems, microanalytical instrumentation, and microfluidic devices to name a few). Limitations of silicon have prevented widespread use of indwelling microdevices specifically oriented toward disease prevention and therapy. More flexible microfabrication methods, especially those that afford mass replication of metal and polymer devices, will provide new opportunities for medical applications of microsystems, such as fastening devices for tissue bonding and wound closure. ${ }^{35-37}$

\section{Summary}

Arrays of microprobes fabricated using silicon micromachining have been used to deliver DNA into cells as an alternative to bombardment and microinjection. These microprobes have been shown to be capable of transecting the internal elastic lamina of normal arteries and penetrating atherosclerotic plaque. Microprobes integrated with a vascular stent are a promising vehicle for delivering drugs or genes to the vessel wall to prevent restenosis. New nonplanar microfabrication technologies are necessary for creating practical devices with cylindrical symmetry; a candidate technology is to microfabricate structures of anodic metal oxides as a replication template.

\section{References and Notes}

1. Henry, S.; McAllister, D. V.; Allen, M. G.; Prausnitz, M. R. In Micromachined Needles for the Transdermal Delivery of Drugs, Proceedings of the Eleventh IEEE International Workshop on Micro Electro Mechanical Systems (MEMS-98), Heidel berg, J anuary, 1998; pp 494-498.

2. Klein, T. M.; E. Wolf, D.; Wu, R.; Sanford, J . C. High Velocity Microprojectile for Delivering Nucleic Acids into Living Cells. Nature 1987, 327, 70-73.

3. Potter, H.; Weir, L.; Leder, P. Enhancer-Dependent Expression of Human $\mathrm{k}$ I mmunogl obin Genes I ntroduced into Mouse Pre-B Lymphocytes by Electrophoration. Proc. Natl. Acad. Sci. 1984, 81, 7161-7165.

4. Hashmi, S.; Ling, P.; Hashmi, G.; Reed, M. L.; Gaugler, R.; Trimmer, W. Genetic Transformation of Nematodes Using Arrays of Micromechanical Piercing Structures. BioTechniques 1995, 19(5), 766-770.

5. Trimmer, W.; Ling, P.; Chin, C.-K.; Orton, P.; Gaugler, R.; Hashmi, S.; Hashmi, G.; Brunett, B.; Reed, M. L. Injection of DNA Into Plant and Animal Tissues with Micromechanical Piercing Structures, Proceedings of the Eighth International Workshop on Micro Electro Mechanical Systems (MEMS-95), Amsterdam, J anuary, 1995; pp 111-115.

6. McNeil, P. L., private communication.

7. Simpson, J . B.; Selmon, M. R.; Robertson, G. C.; Cipriano, P. R.; Hayden, W. G.; J ohnson, D. E.; Fogarty, J. E. Transluminal Atherectomy for Occlusive Peripheral Vascular Disease. Am. J . Cardiol. 1988, 61, 96G.

8. Safian, R. D.; Grines, C. L.; May, M. A.; Lichtenberg, A.; J uran, N.; Schreiber, T. L.; Pavlikdes, G.; Meany, T. B.; Savas, V.; O'Neill, W. W. Clinical and Angiographic Results of Transluminal Extraction Coronary Atherectomy in Saphe nous Vein Bypass Grafts. Circulation 1994, 89, 302.

9. Ahn, S. S.; Auth, D.; Marcus, D. R.; Moore, W. S. Removal of Focal Atheromatous Lesions by Angioscopically Guided High-Speed Rotary Atherectomy. J. Vasc. Surg. 1988, 7, 292.

10. Fourrier, J. L.; Bertrand, M. E.; Auth, D. C.; Lablanche, J. M.; Gommeaux, A.; Brunetraud, J . M. Percutaneous Coronary Rotational Atherectomy in Humans: Preliminary Report. J . Am. Coll. Cardiol. 1989, 14, 1278-1282.
11. Ip, J . H.; Fuster, V.; I srael, D.; Badimon, L.; Badimon, J .; Chesebro, J . H. The Role of Platelets, Thrombin and Hyperplasia in Restenosis after Coronary Angioplasty. J . Am. Coll. Cardiol. 1991, 17, 77B-88B.

12. Forrester, J .; Fishbein, M.; Helfant, R. A Paradigm of Restenosis Based on Cell Biology: Clues for the Development of New Preventive Therapies. J . Am. Coll. Cardiol. 1991, 17, 758-769.

13. Casscells, W. Migration of Smooth Muscle and Endothelial Cells: Critical Events in Restenosis. Circulation 1992, 86 $723-729$.

14. Willerson, J. T.; Yao, S. K.; McNatt, J .; Benedict, C. R.; Anderson, H. V.; Golino, P.; Murphree, S. S.; Buja, L. M. Frequency and Severity of Cyclic Flow Alterations and Platelet Aggregation Predict the Severity of Neointimal Proliferation Following Experimental Coronary Stenosis and Endothelial I njury. Proc. Natl. Acad. Sci. 1991, 88, 1062410628.

15. Baim, D. S.; Grossman, W. Cardiac Catheterization, Angiography, and Intervention, 5th ed.; Williams \& Wilkins: Baltimore, MD, 1995; p 558.

16. Fischman, D. L.; Leon, M. B.; Baim, D. S. A Randomized Comparison of Coronary Stent Placement and Balloon Angioplasty in the Treatment of Coronary Artery Disease. N. Engl. J . Med. 1994, 331(8), 496-501.

17. Baim, D. S.; Grossman, W. Cardiac Catheterization, Angiography, and Intervention, 5th ed.; Williams \& Wilkins: Baltimore, MD, 1995; p 618.

18. Hofling, B.; Huehns, T. Y. Intravascular Local Drug Delivery after Angioplasty. Eur. Heart J . 1995, 16, 437-440.

19. Riessen, R.; Rahimizadeh, H.; Blessing, E.; Takeshita, S.; Barry, J.J .; I sner, J . M. Arterial Gene Transfer using Pure DNA Applied Directly to a Hydrogel-Coated Angioplasty Balloon. Human Gene Therapy 1993, 4(6), 749-758.

20. Riessen, R.; Isner, J. M. Prospects for Site-Specific Delivery of Pharmacologic and Molecular Therapies. J. Am. Coll. Cardiol. 1994, 23(5), 1234-1244.

21. Unterberg, C.; Buchwald, A. B.; Barath, P.; Schmidt, T.; Kreuzer, H.; Wiegand, V.'Cutting Balloon Coronary Angioplasty-I nitial Clinical Experience. Clin. Cardiol. 1993, 16(9), 660-664

22. Kneller, J. R. Penetrating Through Atherosclerotic Plaque into Rabbit Arteries with Microfabricated Probes, M.S. Thesis, University of Pittsburgh, 1997.

23. Feldman, L. J .; Steg, P. G.; Zheng, L. P.; Chen, D.; Kearney, M.; McGarr, S. E.; Barry, J . J .; Dedieu, J . F.; Perricaudet, M. Isner J. M. Low-Efficiency of Percutaneous AdenovirusMediated Arterial Gene Transfer in the Atherosclerotic Rabbit. J . Clin. Invest. 1995, 95, 2662-2671.

24. Kneller, J. R.; Wu, C. C.; Vorp, D. A.; Reed, M. L.; Weiss, L. E.; Borovetz, H. S.; Watkins, S.; Feldman, M. D. The Use of Microfabricated Probes to Penetrate the Internal Elastic Lamina and Intimal Hyperplasia, submitted for publication in Circ. Res.

25. Muller, D. W. M.; Ellis, S. G.; Topol, E. J . Experimental Models of Coronary Artery Restenosis. J . Am. Coll. Cardiol. 1992, 19, 418-432.

26. Fry, D. L. Aortic Evans Blue Dye Accumulation: Its Measurement and Interpretation. Am. J . Physiol. 1977, 232(2), $\mathrm{H} 204-\mathrm{H} 222$.

27. Fry, D. L.; Mahley, R. W.; Suk, Y. O. Effect of Arterial Stretch on Transmural Albumin and Evan's Blue Dye Transport. Am. J. Physiol. 1981, 240, H645-H649.

28. Fry, D. L.; Mahley, R. W.; Weisgraber, K. H.; Suk, Y. O. Simultaneous Accumulation of Evans Blue Dye and Albumin in the Canine Aortic Wall. Am. J. Physiol. 1977, 233(1), $\mathrm{H} 66-\mathrm{H} 79$.

29. Sheehan, D. C.; Hrapchak, B. B. Theory and Practice of Histotechnology, 2nd ed.; Battelle Press: Columbus, $\mathrm{OH}$, 1980; pp 17-18.

30. Sheehan, D. C.; Hrapchak, B. B. Theory and Practice of Histotechnology, 2nd ed.; Battelle Press: Columbus, OH, 1980; p 205.

31. Dizon, R.; Han, H.; Russell, A. G.; Reed, M. L. An I on Milling Pattern Transfer Technique for Fabrication of ThreeDimensional Micromechanical Structures. IEEE J. Microelectromechan. Syst. 1993, 2(4), 151-159.

32. J ansen, $\mathrm{H}$.; de Boer, M.; Otter, B.; Elwenspoek, M. TheBlack Silicon Method IV: The Fabrication of ThreeDimensional Structures in Silicon with High Aspect Ratios for Scanning Probe Microscopy and Other Appli cations, Proceedings of the Eighth International Workshop on Micro Electro Mechanical Systems (MEMS-95), Amsterdam, J anuary, 1995; pp 8893.

33. Tan, S.-S.; Reed, M. L.; Han, H.; Boudreau, R. High Aspect Ratio Microstructures on Porous Anodic Aluminum Oxide, Proceedings of the Eighth I nternational Workshop on Micro 
Electro Mechanical Systems (MEMS-95), Amsterdam, J anuary, 1995; pp 267-272.

34. Nadeem, A.; Mescher, M.; Rebello, K.; Reed, M. L.; Weiss, L.; Feldman, M. Fabrication of Microstructures using Aluminum Anodization Techniques, Proceedings of the Eleventh IEEE International Workshop on Micro Electro Mechanical Systems (MEMS-98), Heidel berg, J anuary, 1998; pp 274277.

35. Han, H.; Weiss, L. E.; Reed, M. L. Mating and Piercing Micromechanical Structures for Surface Bonding Applica- tions, Proceedings of the Fourth IEEE Workshop on Micro Electro Mechanical Systems (MEMS-91), Nara, J apan, J anuary, 1991; pp 253-258

36. Han, H.; Weiss, L. E.; Reed, M. L. Micromechanical Velcro. IEEE J.' Microelectromechan. Syst. 1992, 1(1), 37-43.

37. Reed, M. L.; Weiss, L. E. Tissue Connective Devices with Micromechanical Barbs. U. S. Patent 5,569,272, October 29, 1996.

J S980085Q 